\title{
A PESQUISA COMO PRÁTICA INVESTIGATIVA NA EDUCAÇÃO INFANTIL
}

\author{
Michelle Ribeiro Cavalcante \\ Pós-graduada em gestão e supervisão escolar / Faculdade Santa Fé \\ Pós graduando em docência dos anos iniciais do ensino fundamental \\ das populações de campo e carcerária na EJA \\ Funcionária da Rede Pública Municipal de Teresina/PI \\ Integrante do Núcleo de Pesquisa da linha de \\ Ensino, Formação de professores e Práticas Pedagógicas da UFPI \\ michelle7ribeiro@hotmail.com
}

\section{Introdução}

A pesquisa é um instrumento que busca investigar, buscar, comparar respostas prontas com as descobertas novas, e com isso complementar informações condizentes com o objeto pesquisado.

E na Educação Infantil não poderia ser diferente, já que o próprio RECNEI (Referencial Curricular Nacional para a Educação Infantil), deixa claro que sua função “é contribuir com as políticas e programas de educação infantil, socializando informações, discussões e pesquisas, subsidiando o trabalho educativo de técnicos, professores e demais profissionais da educação infantil e apoiando os sistemas de ensino estaduais e municipais."

A criança é um sujeito social e histórico que está inserido em uma sociedade na qual partilha de uma determinada cultura. É profundamente marcada pelo meio social em que se desenvolve, mas também contribui com ele (BRASIL, 1994). A criança, assim, não é uma abstração, mas um ser produtor e produto da história e da cultura (FARIA, 1999).

A qualidade das experiências oferecidas para esse público é inerente para sua formação, construção de ideias, criar hipóteses, e formular seus conhecimentos, portanto, articular as práticas sociais com a exposição das experiências cotidianas das crianças para a escola, é tornar significativa a sua própria cultura, investigar o porquê de suas colocações e tornar reflexivo as trocas de conversas entre os pequenos.

O objetivo é levá-los a um desafio, de expor "o que já sabem”, pesquisar “o que querem saber”, e analisar “o que já descobriram”, e com isso, a ação educativa ratifica o que o RECNEI e as Diretrizes Curriculares Nacionais para a Educação Infantil, buscarem articular as experiências e os saberes das crianças com os 
conhecimentos que fazem parte do patrimônio cultural, artístico, científico, pertinentes a Educação Infantil.

E foi com esse propósito maior, da pesquisa socializada, e de expor e colher as informações coniventes com a própria cultura, que o CMEI TIA CARLOTA, da cidade de Teresina/PI, manifestou através do seu trabalho que abordava a água, conduzir esse tema com a experiência da gelatina, já que seria inevitável não abordar suas propriedades e envolver uma série de outros elementos. Essa atividade foi além do esperado, quantos questionamentos, conversas, perguntas, enfim, diálogos que foi além do assunto em questão. Não podia perder de vista esta maravilhosa experiência, que proporcionou muitas outras ideias e expectativas, além de otimizar e refletir minha própria práxis , e transformar essa pesquisa em uma documentação pedagógica.

\section{A experiência da gelatina como fonte de pesquisa}

As crianças ficaram tão maravilhadas com o experimento, que surgiram outras trocas de conversas, como cores, já que tínhamos um recipiente com gelatina amarela e outra recipiente com a cor vermelha, "porque misturar água fria com gelada?", "temos que colocar na geladeira?", "vai demorar muito ficar pronta?", enfim, foram tantas indagações, mas todas tiradas durante a atividade. Algumas crianças nunca tinham provado uma gelatina, outras gostaram e outras já comeram até a dos outros.

A própria ação proporcionou pistas para adentrar no que queremos alcançar, e a apropriação significativa nas crianças. Esse modo contextualizado, utilizando estratégias condizentes com seu desenvolvimento infantil gerou expectativas em torno de suas próprias vivências, o que foi nos orientando à medida em que estávamos frente a frente com a própria atividade.

Durante a experiência, foi dividido um grupo para a distribuição dos ingredientes, água fria e quente, os pozinhos das gelatinas, e outro grupo para colocar no copo de cada um, para que todos pudessem provar juntos, fator preponderante presente foi a relação harmoniosa que tiveram uns com os outros, respeitando o seu conhecimento de mundo, seus valores e a individualidade de cada uma, contribuindo para manter a auto-estima do grupo. 
Trata-se de interação social, um processo que se dá a partir e por meio de indivíduos com modos histórica e culturalmente determinados de agir, pensar e sentir, sendo inviável dissociar as dimensões cognitivas e afetivas dessas interações e os planos psíquico e fisiológico do desenvolvimento decorrente (VYGOTSKI, 1986 e 1989). Nessa perspectiva, a interação social torna-se o espaço de constituição e desenvolvimento da consciência do ser humano desde que nasce (VYGOTSKI, 1991).

A visita na cozinha da escola para deixar a gelatina no congelador também foi outra porta a ser aberta para discussões, logo, puderam perceber que o ambiente era diferente do de suas casas, porém, as exposições de suas falas ao observarem os objetos contidos na cozinha era excitante para cada um deles, pois expunham sua vida social, "a mamãe não deixa eu chegar perto do fogão", “eu abro a geladeira pra pegar o litro d'água", "eu não posso abrir o forno", "eu já vi a mamãe colocar a carne no congelador", diálogos foram se constituindo num varal de conversas.

Desta forma, o que é plausível nessa experiência é, sem dúvida, a "criação" e o "desenrolar" das pesquisas em si, apresentando as áreas do conhecimento, em que o resultado dessa colheita do conhecimento possa ser conseqüência de uma prática reflexiva e comprometida com os saberes pedagógicos.

Neste processo de investigação, coube analisar as relações educativas com o projeto político pedagógico da escola que prima por uma visão de atribuir a pesquisa como estrutura subjacente responsável a aprendizagem significativa das crianças, e que foi possível visualizar, sentir, que não é um elemento utópico, é real, e que é fundamental para o fenômeno "El educativo".

O que caracteriza a investigação educacional é como dizia Sacristán (1978, p.165 -166), o fato dela ir "perseguindo a sombra que ela mesma tem que ir criando". Esta particularidade estabelece o casamento entre a teoria-prática para minhas práticas e saberes.

Sobre a particularidade do estudo pedagógico concordam até mesmo aqueles que, como Anísio Teixeira (In: Brandão \& Mendonça, 1997, p. 202), distinguem a educação da ciência, situando nas chamadas 'ciências-fontes' a responsabilidade por (...) dar um caráter mais científico à ação desenvolvida no campo educativo".

E durante toda essa investigação, tudo foi registrado, com fotos, falas, escritos, cada olhar fixo era um fleche, adotar essa prática serve para perceber como o desenvolvimento dos alunos serviu de contributo para o planejamento, fez-me analisar a 
importância que a prática investigativa na educação infantil é fundamental para que as crianças possam construir, reconstruir seus conhecimentos, contar seus "ensaios" é ampliar e respeitar seus conhecimentos prévios.

Entendo que essa investigação educacional depende não de um caráter idealista, mas de colaborar com as perspectivas educacionais almejadas, e de ampliar essa interconexão entre buscar e praticar pedagogicamente, influenciando nesse espaço de transformação a âncora que caracteriza a prática social histórica.

Em consonância com o RECNEI, "esse processo possibilitará a elas modificarem seus conhecimentos prévios, matizá-los, ampliá-los ou diferenciá-los em função de novas informações, capacitando-as a realizar novas aprendizagens, tornandoas significativas."

A maior relevância desse projeto é oportunizar as crianças, um ser crítico, capaz de fazer a diferença em pequenas situações do dia a dia, é resgatar seus costumes e como também ampliar sua capacidade de interação com o conhecimento, o que se verificou durante o desenvolvimento do trabalho.

Faz-se referência ao parágrafo anterior que Rocha (2001), afirma que ao “articular o conhecimento prévio e as experiências práticas na construção do conhecimento novo, permitindo dar a voz aos sujeitos envolvidos com o problema e permitindo ao pesquisador uma posição de compartilhamento que eu chamaria de diferenciada". O que caracteriza a ponte do que a criança já sabe e o que ela acaba descobrindo no decorrer das atividades, como diz Gouveia $(1994$, p.68) "por trazer um conhecimento de quem pode e deve ir além do senso-comum, modalidade esta que é respeitada mas deve ser superada, exatamente onde a pesquisa possibilita ultrapassar a mera inserção prática".

De fato, foi interessante os olhares de cientistas mirins, o interesse que manifestavam pelo experimento, "as informações que era tirado deles", de forma lúdica, uma conversa totalmente infantil, o conhecimento de mundo que era absorvido por eles, era fantástico, foi uma grande oportunidade de ter esses ensaios como documentação pedagógica.

Essa prática deveu-se também as produções que subseqüentes iria proporcionar a mim, como professora de construir na própria história dos alunos, o fato de ampliar meu olhar pesquisador, de otimizar as metodologias e práticas pedagógicas, que ao mesmo tempo auxilia no resgate histórico, de entender e compreender o deslanche político da Educação Infantil. A presença constante do "preocupar-se" com as 
práticas pedagógicas implementadas no cotidiano das salas de aula apresentando-se muitas vezes como um campo de batalha ou quem sabe de um mundo tão distante na busca da definição da função para o público vigente (no caso, a Educação Infantil); por fim, pretende-se relevar que através de toda essa trajetória, é uma forma também de aprimorar cada vez mais nossa práxis e de registrar, pois o registro é um documento fidelíssimo para acompanhar nossos progressos, conquistas, anseios e expectativas, buscando constantemente incorporar o verdadeiro caráter histórico-político, social e cultural da escola, e nada mais, nada menos que mantê-los como fontes, documentos de observar o presente e preparar-se para o futuro.

Em consonância ao trabalho, o Prof ${ }^{\circ}$ Manuel J. Sarmento Titular do Instituto de Estudos da Criança da Universidade do Minho, em Portugal, em uma entrevista para a revista da criança, diz acreditar que, "seja na educação infantil, seja no ensino fundamental, a educação pode fazer a tradução entre a cultura escolar e as culturas infantis. Significa potencializar esses modos de simbolização do real no trabalho pedagógico. Há uma tendência de que algo seja construído nesse sentido, a partir da educação infantil e das propostas da pedagogia da infância. Suponho que é possível fazer um trabalho educativo que não se centre apenas na dimensão cognitiva do aluno, que não feche a porta para a criança que vive em cada aluno. É possível fazer que essa dimensão cognitiva aproveite as qualidades dos pequenos e, portanto, apreenda também sua forma de relação com a cultura e seu modo de interação com os outros." (no 45, dezembro de 2007).

O principal resultado dessa atividade realizada foi possibilitar as crianças estabelecer múltiplas relações, ampliar suas ideias sobre o assunto específico assim como "administrar" a interdisciplinaridade dos diferentes eixos, buscando a complementação dos conhecimentos pertinentes as diferentes áreas que vão se manifestando através de suas suposições e colocações ditas pelas crianças.

Ao alcançar o nível de êxito da atividade, a conclusão respaldada foi na atenção que as crianças se comportavam frente a experiência, suas falas, suas posturas, uma produção que foi além das minhas expectativas, uma produção a nível acadêmico, capaz de analisar e compreender a forma de pensamento da criança e de saber intervir com o objetivo de contribuir para sua aprendizagem significativa, um fator marcante para seu meio cultural e social das crianças. 


\section{A pesquisa crítico-colaborativo frente a experiência da gelatina}

A pesquisa na educação infantil torna-se colaborativa a partir do momento que a criança descobre,critica, discute, e torna-se significante para sua aprendizagem, transita pelos seus contextos, de onde provêm temas que irá complementar ou desenvolver sua condição de ver o mundo e apreender para sua própria realidade.

Tomando por essa última ideia, que ainda manifesta-se tímida no universo infantil, temos os teóricos que mediante suas práticas e observações, Vygotsky e Piaget, tem como base em suas pesquisas, que a criança precisa interagir para construir, e que tanto os aspectos como brincar, conversar, experimentar, balizam o verdadeiro sentido da investigação cientifica.

Ao revelar essa análise, a perspectiva da interação visa justamente atribuir a essa influência, o senso crítico e colaborativo por parte das crianças, e frente a esse resultado perceber que a função da escola corrobora os valores éticos, ideológicos, políticos. Partilhar essas experiências significa atribuir a crença de que o conhecimento construído figura com os sujeitos envolvidos (no caso, da coletividade), e não sobre os mesmos.

Como Liberali (2008, p. 26) afirma que,

\footnotetext{
Entende-se que é abstraindo os conceitos cotidianos (individuais e não conscientes) sobre a própria prática de ensino-aprendizagem através de sua relação com a teoria formal (conceitos científicos, ou seja, abstrações hierarquizantes dadas pela cultura), que haverá possibilidade de consciência do próprio fazer pedagógico num sentido mais amplo. Entender estes conceitos científicos possibilita uma revisão da própria ação, seu questionamento e transformação aplicada, uma vez que parte da realidade concreta do sujeito, abstrai teoricamente através da voz de outros e redimensiona internamente para criar externamente.
}

Construir, reconstruir e transformar é relativo ao conceito de Piaget, quando se refere que a aprendizagem acontece através de equilíbrios e desequilíbrios. Premente a esse conceito, é possível desempenhar uma transformação social, onde a crítica manifesta-se através da interação um com o outro.

Concomitante a essa mudança, construir e reconstruir tornam-se peça única quando se trata de majorar o olhar para a Educação Infantil, atinentes a práticas cotidianas que constrói sua identidade, aprende, observa, dialoga, questiona e, produz cultura. 
Uma cultura social que relega o sentido histórico que ainda permeia nas ambiências escolares, de "manter" uma visão assistencialista, de minorar ou até mesmo de regular suas práticas, mas, de ver a educação atrelada a autonomia, responsabilidade, respeito, de direitos de cidadania, etc.

Ao compactuar com os princípios citados acima, a escola deve não apenas apostar na mudança, mas refletir em cima da mesma, apropriando-se, renovando e articulando esses conhecimentos construídos e internalizados, em diferentes linguagens, assim como outras propostas sugeridas e afincadas para a Educação Infantil.

A mudança é fruto da reflexão sobre o ato, a experiência, que auxilia no processo dialético, com isso, nos torna sujeitos de um processo histórico, valoriza e ao mesmo tempo amplia nossas experiências, e o melhor, possibilita movimento, recriar contextos significativos.

\section{A prática docente diante da pesquisa}

$\mathrm{O}$ que mais tornou-se interessante na proposta de realizar essa experiência com as crianças, foi observar que essa prática foi significante para a mudança, de rotina, de planejamento, de realizar uma atividade que chamasse a atenção dos pequenos e quanto efeito "contaminou" ambas as partes. Também não posso desconsiderar que as vezes perguntava como poderia organizar uma atividade que cutucasse a curiosidade dos meus alunos, que fizessem despertar ao mesmo tempo o que sabiam, o que pensavam, e diante desses ensaios, o fazer e o agir que são precípuos para a avaliação da prática.

A partir desse momento, de discussões coletivas, diálogos emergem como um coral de vozes, ao mesmo tempo, um colocando suas opiniões e através dessas conversas, que a atividade em grupo envolve todos, é um processo de colaboração. Essa ideia de que o professor "sabe" de tudo, possui dos lados, pois esse artifício permite a troca, de como a pesquisa torna-se uma grande e possível possibilidade para cindir essa postura de detentor.

E através dessa reflexão, partindo do processo experimental, que a identidade do professor e da escola toma um novo rumo, ritmo, comprometidos com o desenvolvimento de habilidades concernentes com a Educação Infantil. 
Também se deve pensar que práticas como estas, oportunizam a formação dos educadores, que é pensar também em oferecer uma educação de qualidade, é atentar para a construção de uma identidade e de compreender a história oriunda de lutas e controvérsias, e de atribuir a pesquisa como desafio para a prática docente.

O que se quer apresentar nesse momento é como a pesquisa contribui para a formação profissional, escolar, científica, busca-se sanar dúvidas quanto o processo de organização de ideias, a estrutura do pensamento da criança, e para isso, além de leituras, estudos, a pesquisa nesse e noutros momentos tornam-se significativos para a compreensão do mundo infantil.

O que se observa é que além da angústia de muitos educadores quanto ao processo de ensino-aprendizagem, deve-se a formação acadêmica, que muitas das vezes não são oferecidas de forma coerente com a realidade, uma educação que não nos é apresentada na universidade, e que ao sairmos da instituição nos deparamos com uma situação totalmente fora da realidade. Essas dúvidas devem ser expostas em discussões sobre a reforma curricular dos cursos que formam os futuros docentes.

Cabe acentuar que a pesquisa como prática investigativa é uma análise sobre as atividades, começo, meio e internalização por parte dos envolvidos, dos resultados e da intervenção do professor no processo. Essa postura comunga com os valores sociais, éticos e estéticos que irão informar sobre o resultado alcançado, observar suas reais contribuições, impasses, conflitos, indicar perspectivas, reestruturar suas identidades para otimizar futuros trabalhos.

A proposição a partir das problematizações no decorrer das discussões serve de aparato para a formação dos educadores, pois se não considerarmos essas práticas, não se dá o valor para a reflexão, do retorno, de fazer diferente.

Vale ressaltar,

O currículo escolar é um lugar de circulação das narrativas, mas, sobretudo, é um lugar privilegiado dos processos de subjetivação, da socialização dirigida, controlada. Costa (2005, p. 51)

São oportunidades para ampliar o nível de informação para as crianças, pois suas narrativas exemplificam o que já sabem e através das discussões, constrói se em seu mundo uma aprendizagem mais que significativa, ratifica-se uma política cultural constituída em uma "arena da luta pela fabricação e consolidação das identidades (Costa, 2005: 52)". 
Constatar essas reflexões percebe-se a necessidade de ter como fonte a fundamentação teórica, pautada nas pesquisas de estudiosos, e que podem servir de subsídio para nossas representações profissionais.

Em fundamento, o Plano nacional de Educação (PNE) de 2001 reforça em seu texto que:

\begin{abstract}
a formação dos profissionais da educação infantil merecerá uma atenção especial, dada a relevância de sua atuação como mediadores no processo de desenvolvimento e aprendizagem. A qualificação específica para atuar na faixa de zero a seis anos inclui o conhecimento das bases científicas do desenvolvimento da criança, da produção de aprendizagens e a habilidade de reflexão sobre a prática, de sorte que

esta se torne, cada vez mais, fonte de novos conhecimentos e habilidades na educação das crianças (BRASIL, 2001a).
\end{abstract}

Ao deparar com elementos teóricos que fundamentasse a minha pesquisa frente a experiência, possibilitou para minha práxis, atenuar desde a fala das crianças até a aplicação dos diferentes instrumentos, foi uma maneira de entender a estrutura de suas colocações, da curiosidade que tinham em buscar novas fontes, da "curiosidade epistemológica" (FREIRE, 2008) e para promover minha identidade profissional.

Nóvoa (1995, p. 25) afi rma que "a formação não se constrói por acumulação (de cursos, de conhecimentos ou de técnicas), mas sim através de um trabalho de reflexividade crítica sobre as práticas e de (re)construção permanente de uma identidade profissional".

Posterior a essa colocação, o próprio Referencial Curricular Nacional (RCN) para a educação infantil brasileira aponta como meta de qualidade.

\begin{abstract}
O trabalho direto com crianças pequenas exige que o professor tenha uma competência polivalente. Ser polivalente significa que ao professor cabe trabalhar com conteúdos de naturezas diversas que abrangem desde os cuidados básicos essenciais até conhecimentos específicos provenientes das diversas áreas do conhecimento. Este caráter polivalente demanda, por sua vez, uma formação bastante ampla do profissional, que deve tornar-se ele também um aprendiz, refletindo constantemente sobre sua prática, debatendo com seus pares, dialogando com as famílias e a comunidade e buscando informações necessárias para o trabalho que desenvolve. São instrumentos essenciais para a reflexão sobre a prática direta com as crianças a observação, o registro, o planejamento e a avaliação (BRASIL, 2001b, p. 41).
\end{abstract}

Conforme o referencial, não é mais aceitável um professor com pouca bagagem ou sem formação específica, é necessário articular aspectos subservientes para o desenvolvimento infantil, é buscar e desenvolver um trabalho embasado no 
planejamento flexível, que envolve instrumentos como registro e a avaliação diante das atividades.

Subsequente ao referencial, a LDB n9394/96, art. 62, enfatiza

“A formação de docentes para atuar na educação básica far-se-à em nível superior, em curso de licenciatura, de graduação plena, em universidades e institutos superiores de educação, admitida, como formação mínima para o exercício do magistério na educação infantil e nas quatro primeiras séries do ensino fundamental, a oferecida em nível médio, na modalidade Normal."

Verifica-se que a formação inicial é inerente para a prática e concomitante, desvencilha para uma prática embasada em aspectos cognitivos, emocionais, psicomotor e social, considerando aspectos de sua própria realidade social e cultural.

Paulo Freire (2008, p. 29) sustenta que,

no meu entender o que há de pesquisador no professor não é uma qualidade ou uma forma de ser ou de atuar que se acrescente à de ensinar. Faz parte da natureza prática do docente a indagação, a busca, a pesquisa, o de que se precisa é que, em sua formação permanente, o professor se perceba e se assuma, porque professor, como pesquisador.

A concepção de Freire ao se referir ao professor pesquisador, condiz a sua postura como profissional político que revela para seus alunos, um discurso reflexivo, que permita o encontro entre a pesquisa sobre a sua prática, objetivando a produção de conhecimento.

Essa pesquisa possibilitou bem como mudanças pertinentes para a promoção da identidade profissional, política e social para minha formação docente, além de suscitar uma postura pesquisadora, a busca por uma práxis transformadora.

As conversas em roda, foram gerando momentos de reflexão que durante as colocações, possibilitou ocasiões para aplicar estratégias e refletir sobre a prática, ressalvando as possíveis mudanças, um ponto de partida para ressignificar a práxis.

Momentos de interação com os pais, alunos, foram pertinentes para elaborar um planejamento que majorasse as propostas da atividade, assim como, observar e redigir os relatos percebíveis, a relação de respeito e compromisso com todos os envolvidos, minha formação docente.

Como afirma Esteban e Zacur, 
a prática é o ponto de partida. [...] Dela emergem as questões, as necessidades e as possibilidades [...]. Parte-se da prática para voltar a ela. Porém, na volta, não se encontra a mesma prática inicial, há uma nova qualidade na medida em que o movimento ação-refl exão-ação gera transformações, que permitem avançar em direção à melhor compreensão do fenômeno, relativizando o imediatamente perceptível (ESTEBAN; ZACUR, 2002, p. 21-22).

O trabalho coletivo é fundamental para socializar diálogos, é uma estratégia fundamental para a pesquisa, não tendo a teoria como ponto culminante para esclarecer as dúvidas, mas para suscitar através da experiência, uma maneira de complementar, integrando ambas as partes ( no caso, a teoria e a prática), como aliados na busca do bem comum - a práxis. Como menciona Freire (2008, p. 39), “[...] na formação permanente dos professores, o momento fundamental é o da reflexão crítica sobre a prática. É pensando criticamente a prática de hoje ou de ontem que se pode melhorar a próxima prática".

Fundamentar na prática é uma forma de oportunizar em cima da pesquisa, um estudo teórico na busca pelo produto investigativo, um desafio que se compromete em transformar a criança, o professor, de agente para sujeito participante, e não resultantes de mera adaptação. Deve-se relevar que a mudança nasce o movimento, uma tomada de atitude para a transformação, e daqui por diante, já se sabe qual a direção que se é tomada. 


\section{Considerações Finais}

A Educação Infantil não sustenta apenas a ideia de cuidar, de assistencialista, já que com a constituição de 88 , a modalidade passa a ter uma nova visão de educação, uma voltada para os aspectos cognitivos, emocionais, sociais, psicomotor e etc.

É importante destacar que se a Educação Infantil conquistou princípios e diretrizes oriundos de lutas, pesquisas e estudos de teóricos e educadores que acredita que a educação básica, é a base para construção e desenvolvimento do ensino-aprendizagem.

E essa pesquisa com os alunos proporcionou mais que uma mudança, mas aprender e conhecer na ação educativa como desafio para minha práxis. Essa transformação desempenhou um papel significativo quanto ao planejamento, avaliação, registro, enfim, foi possível perceber a minha atuação frente a essa atividade crítica-colaborativa.

Entendeu-se que a pesquisa como prática investigativa é vista a partir do pressuposto a ser descoberto, mas utilizando a interdisciplinaridade como meio para a intervenção, já que uma área precisa da outra.

Essa mudança teve uma ascendência significativa para a formação docente, pois ao planejar com o objetivo de atribuir com a sua realidade cultural uma ação educacional, e foi através da experiência que se concretizou. 
O sucesso dessa aula foi extremamente significativo para crianças quanto para minha prática, serviu de embasamento para muitas colocações. Inclusive sustentar a ideia para outras práticas que farão de um "simples tema" uma oportunidade de alavancar conhecimentos.

Desenvolver uma experiência na educação Infantil é muito mais que elaborar uma atividade para levar para casa e no dia seguinte ser feita ou não, e não manifestar nas crianças nenhum senso crítico e significativo. É oportunizar aos pequenos um momento de análise, de descobertas, de perceber o que já sabiam, servir de base para complementar com o conhecimento oferecido, e dessa forma oferecerem para a realidade, para as famílias, para a escola, mais que uma produção, uma experiência, mas, um conhecimento científico, um olhar pesquisador.

Ressignificar a práxis significa dizer, a mudança através do movimento, da reflexão da prática docente, é observar através da mediação pedagógica, a construção do saber.

Portanto, utilizar a pesquisa como instrumento para construção no processo do ensino-aprendizagem é acreditar que a educação deve ter o compromisso com a transformação político-cultural para nossas crianças 


\section{Referencias bibliográficas}

ALMEIDA, Ordália Alves de (2001) - O dito e não feito - o feito e não dito: em busca

do compasso entre o falar e o fazer na educação infantil - São Carlos/SP: UFSCAR, tese de doutorado

ARIÈS, Philippe. História social da criança e da família. Rio de Janeiro: Guanabara, 1981.

BALDWIN, Sefod L. Teorias do desenvolvimento da criança. São Paulo: Pioneira, 1973.

BOFF, L. Saber cuidar: ética do humano - compaixão pela terra. 16. ed. Petrópolis: Vozes, 1999.

BONDIOLLI, Ana; MANTOVANI, Susana. Manual da Educação Infantil. Porto Alegre, RS: Artes Médicas, 1999.

BRANDÃO, Zaia e Mendonça, A. W. (org.): Por que não lemos Anísio Teixeira. (Coleção da Escola e Professores), Rio de Janeiro, Ravil, 1997.

BRASIL. Ministério da Educação. Plano Nacional de Educação. Brasília: Inep, 2001. Ministério da Educação. Secretaria de Educação Fundamental. Referencial curricular nacional para a educação infantil. Brasília: MEC, 2001.

Lei $\mathrm{n}^{\circ}$ 9.394, de 20 de dezembro de 1996. Estabelece as diretrizes e bases da educação nacional. Diário Oficial [da] República Federativa do Brasil, Brasília, DF, 23 dez. $1996 . \quad$ Disponível em: http://www.planalto.gov.br/ccivil_03/LEIS/L9394.htm. 
Ministério da Educação e do Desporto. Secretaria de Educação Fundamental Geral de Educação Infantil. Proposta pedagógica e currículo para a educação infantil: um diagnóstico e a construção de uma metodologia de análise. Brasília, MEC/SEF/DPE/COEDI, 1996.

Diretrizes Curriculares Nacionais para a Formacao de Docentes da

Educacao Infantil e dos Anos Iniciais do Ensino Fundamental, em Nivel Medio, na Modalidade Normal. Resolucao CNE/CEB nº 2, de 19/04/1999a.

CAMPOS, Maria Malta. Educação infantil: o debate e a pesquisa. Cadernos de Pesquisa, n. 101, p.113-127, jul. 1997.

Profissionais de educacao infantil: desafios para a política educacional. In: SEVERINO, A. J.; FAZENDA, I. C. A. (Orgs.). Politicas educacionais: o ensino nacional em questao. Campinas: Papirus, 2003. p. 151-161 (Serie Cidade Educativa).

CERISARA, A. B. A produção acadêmica na área de educação infantil a partir da análise de pareceres sobre o Referencial Curricular Nacional de Educação Infantil: primeiras aproximações. In: FARIA, A. L. G.; PALHARES, M. S. (orgs) Educação Infantil pós-LDB: rumos e desafios. Campinas: Autores Associados. São Carlos: Editora UFSCar. Florianópolis: Editora UFSC, 1999.

COSTA, Marisa Vorraber; SILVEIRA, Rosa Maria H. Produzindo subjetividades femininas para a docência: um estudo da revista Nova Escola. Porto Alegre: UFRGS/ FACED. Relatório de pesquisa apoiada pela Fundação Carlos Chagas.

DUARTE, Newton. A escola de Vygotsky e a Educação escolar (hipótese para uma leitura pedagógica da Psicologia Histórico Cultural). In: E. escolar. Teoria do Cotidiano e a Escola de Vygotsky. São Paulo, 1996.

FARIA, Ana Lucia Goulart. Educacão pre-escolar e cultura. Sao Paulo: Cortez, 1999.

FRABONI, Franco. A escola infantil entre a cultura da infância e a ciência pedagógica e didática. In:ZABALZA, Miguem A. Qualidade em educação infantil. Trad. Beatriz Affonso Neves. Porto Alegre: Artes Médicas.1998.

FREIRE, P. Pedagogia da autonomia. São Paulo: Paz e Terra, 2008. 
FORMOSINHO, J. A universidade e a formação de educadores de infância: potencialidades e dilemas. In: MACHADO, M. L. de. Encontros e desencontros em Educação Infantil. São Paulo: Cortez, 2002

GIROUX, H. Praticando estudos culturais nas faculdades de educação. In: SILVA, T. T. (org.) Alienígenas na sala de aula. Petrópolis: Vozes, 1995.

GOUVEIA, Aparecida J.: Notas a respeito das diferentes propostas metodológicas apresentada. Cadernos de Pesquisa. São Paulo, n 49, pp. 67-70, mai-1994.

KUHLMANN, Jr., Moysés.: Infância e Educação Infantil: uma abordagem histórica. Porto Alegre, Mediação, 1998.

KUHN, Tomás S.: A estrutura das revoluções científicas. São Paulo, Editora Perspectiva, 1992.

LIBERALI, F.C. Formação crítica de educadores: questões fundamentais. Taubaté/SP: Cabral Editora e Livraria Universitária, 2008 (p.26).

MACHADO, M. Lucia de A. Formacao profissional para educacao infantil: subsidios para idealizacao e implementacao de projetos. Tese de Doutorado. PUC/SP, 1998.

MEC/SEF/DPE/COEDI.: Propostas pedagógicas e currículo em educação infantil. Brasília, 1996.

MONTESSORI, Maria. Pedagogia científica. A descoberta da criança. Trad. Aury Asélio Brunetti. São Paulo: Editora Flamboyant, 1965.

MOREIRA, A. F \& SILVA, T. T. (Org.) Currículo, cultura e sociedade. São Paulo: Cortez, 1994.

NÓVOA, A. (Org.). Os professores e a sua formação. Lisboa: Dom Quixote, 1995.

OLIVEIRA, Anne Marie Milon. Célestin Freinet - Raízes Sociais e Políticas de uma Proposta Pedagógica. Rio de Janeiro: Papéis e Cópias da Escola de Professores, 1996.

ROCHA, Eloísa Acires Candal. A pedagogia e a educação infantil. São Paulo: Revista Brasileira de Educação, jan/fev/mar/abr, nº.16, 2001. 
A pesquisa e educação infantil no Brasil: trajetória recente e perspectivas de consolidação de uma pedagogia. Tese (Doutorado) - Campinas, 1999.

SACRISTÁN, José. G.: Explicación, norma y utopía en las ciencias de la educación. In: Escolano A. y otros. Epistemología y educación. Salamanca, Ed. Sígueme, 1978.

SPINK, J. P. (Org.). O conhecimento no cotidiano: as representações sociais na perspectiva da psicologia social. São Paulo: Brasiliense, 1995.

VASCONCELLOS, V. M.R. Formação dos profissionais de educação infantil. Reflexões sobre uma experiência. Em Aberto, Brasília, Inep, 2001.

VYGOTSKY, L. S. A formacao social da mente. O desenvolvimento dos processos psicologicos superiores. Sao Paulo: Martins Fontes, 1989.

WEIZ, Telma. Revendo a função pedagógica da pré-escola. In: Caderno Ideias. São Paulo: FDE, 1994. 